\title{
The Synergistic Effect of Zeolite, Date Stones Activated Carbon and Sand in the treatment of Greywater Including Kitchen Waste.
}

\author{
Ahmed M. Abou Elmagd \\ Sanitary and Environmental Engineering, Faculty of Engineering at Shoubra, Benha University, Egypt. \\ Correspondence Author: Ahmed M. Abou Elmagd, Assistant Professor of Sanitary and Environmental Engineering, Faculty of Engineering at Shoubra, Benha \\ University, Egypt \\ E-mail:- ahmed.mahmoud@feng.bu.edu.eg, ahmedcivil2003@yahoo.com
}

Received date: 11 June 2019, Accepted date: 28 July 2019, Online date: 8 August 2019

Copyright: (C) Ahmed M. Abou Elmagd, This is an open-access article distributed under the terms of the Creative Commons Attribution License, which permits unrestricted use, distribution, and reproduction in any medium, provided the original author and source are credited.

\begin{abstract}
The world's attention has turned to greywater recycling as an emerging strategy that is being implemented worldwide to supplement water resource portfolios. greywater recycling face two challenges, a very high cost to construct a separate greywater network and the high concentrations of pollutants as a result of including kitchen waste as a part of greywater, especially in our Arab world. This paper focused on the design of an in situ, cheap and easy to use graywater treatment plant by using of natural materials in filtration and without any chemicals addition. Pre-treatment by sedimentation and flotation were used to decrease organic loads before main filtration. Combined action of pre-treatment process succeeded to remove $45 \%$ of TSS, 37\% of BOD and 35\% of COD. Four different filtration medias were used;sand mixed with zeolite (SMZ), Date seeds activated carbon (DSAC), red Zeolite and black Zeolite. The best removal was achieved by SMZ, it was $89 \%$ for TSS, $83 \%$ for BOD and $79 \%$ of COD. Also, DSAC achieved the second-best removal efficiency. Black Zeolite and Red Zeolite achieved the third best removal efficiencies, they were almost having the same removal performance. For the best serial arrangement of these filtration media, three series were tested; series $1(\mathrm{SMZ}+\mathrm{Zeolie})$, series 2 (SMZ+DSAC) and Series 3 (SMZ+DSAC+Zeolite). Results have demonstrated that Series 3 showed the best removal performance with up to $\mathbf{9 8} \%, 95 \%, 93 \%$ and $\mathbf{9 7} \%$ for TSS, BOD, COD, and turbidity respectively. Series 3 removal performance over time was then checked to measure the decrease in removal efficiency with time, In addition to predict how long time will be required for the filtration medias to reach the clogging and so backwash will be required then. The removal efficiency after 6 hours decreased by $6 \%, 5 \%$ and $6 \%$ for TSS, BOD and COD respectively, and the theoretical overall time required to reach blockage was $98 \mathrm{hr}$.
\end{abstract}

Keywords: Zeolite - Date stones activated carbon - Greywater - Kitchen waste.

\section{INTRODUCTION}

Most of the researches that studied the treatment of greywater, concerned with the treatment of waste generated from sinks, bathtubs, showers and laundries without including kitchen waste. This may be suitable for some drainage systems like "one-pipesystem"; which may be common in Europe, while the conventional drainage system in the Arab world is the "two-pipe-system". According to this system, the first pipe was to drain the toilet wastewater (Blackwater) with diameter not less than 4 inches, while the other pipe was to drain all other wastes including kitchen with diameter, not less than 3 inches. To design an in-situ household greywater treatment unit, it would have to include kitchen drainage. This study was conducted to develop this unit. Greywater recycling is a promising strategy being implemented all over the world to compensate shortage in water resource portfolios [1]. The amount of greywater represents about $50 \%$ to $70 \%$ of all the wastewater disposed of by household [2].

Greywater treatment techniques should satisfy 4 criteria: hygienic safety, aesthetics, environmental tolerance, and economic feasibility, [3]. Also, Gross et al. (2007) [4] added a fifth important aspect, namely that these systems should be easily maintained by unskilled operators. However, these economic and technical aspects remain a challenge for the implementation of these systems [5]. Techniques of greywater treatment include physical, chemical, biological, and natural systems or a combination of these $[6 ; 7]$. Natural greywater treatment techniques are considered the most environmentally friendly and cost-effective technology for greywater treatment and reuse [6;7]. Natural greywater treatment systems such are systems that use natural media for filtration and biological degradation.

Most of the natural zeolite is of volcanic origin [8]. Zeolite has an aluminosilicate feature, just like clay [9], but it does not dissolve in water due to rock characteristics, which it gains from heating in volcanic conditions. Zeolites are microporous 
aluminosilicate minerals with a three-dimensional framework of $\mathrm{AlO} 4$ and $\mathrm{SiO} 4$ tetrahedral [10]. The tetrahedrons are bound together by covalent bonds over ordinary oxygen atoms forming interconnected cages and channels [11; 12].

Regarding the Mechanism of zeolites for the removal of contaminants, the aluminosilicate structure in the zeolite creates a negative charge, which is balanced by the cation on the surfaces, these cations are bonded by weak electrostatic forces, therefore, these cations in zeolites can be exchanged by the cationic pollutants in greywater such as the cationic surfactants, sodium, ammonium, and also amphoteric surfactants in acidic $\mathrm{pH}[13,14,15]$. This significant advantage seems to have one drawback, the surface cations in the Zeolite released in water and increase total dissolved salts.

Organic compounds also can be removed by cationic surfactant modified zeolites because the hydrophobic tail group forms partitions, where the organic compounds get trapped. Some of the zeolite types have a large surface area, 520 $\mathrm{m} 2 / \mathrm{g}[16]$. Therefore, these zeolites can be used to remove the other pollutants from greywater by adsorption. Zeolite framework has channels and interconnected voids of discrete size (3-20 $\AA$ ). Therefore, large molecules have no access to the internal surface and adsorb only to the external surface [17].

Granular activated carbon from natural source material such as black coal, charcoal, coconut shell uses the adsorption (Physisorption) property to remove pollutants from greywater/wastewater by pollutant adhering to the surface of the activated carbon. This attachment is due to the physical forces such as the Van der Waals forces and adhesion of contaminants to the surface of the material due to chemical bonding (Chemisorption) [18, 20, 13]. The other characteristics such as the large surface areas $(800-1,500 \mathrm{~m} 2 / \mathrm{g})$, microporous structure, nonpolar features (Hydrophobic) and due to its economic viability makes it more suitable for water or wastewater purification [13, 18]. Therefore, activated carbon can be used to remove the greywater characteristics regardless of their chemical properties due to adsorption.

Fruit stones are of particular interest as by-products from food processing industries, in sufficient quantities for obtaining good adsorbing carbons with remarkable hardness and better porous structure [19]. Peach stones [22; 22], apricot stones [23, 24]. live stones [25;26], cherry stones [27; 28], grape stones [29; 30], and date stones [31; 32]. It was effectively used as sources for the production of activated carbon with high surface areas and high porosity ratios of all agricultural waste, date stones are considered one of the best resources for the production of $\mathrm{AC}$ because of their high carbon content, low price, and quite availability, especially in Mediterranean countries [33, 34]. About $10 \%$ of the fruit is waste in the form of stones, making them the largest agricultural by-product in palm growing countries with an approximate amount of 700 thousand tons [35; 36].

\section{MATERIALS AND METHOD}

The main objectives of this study were to evaluate the feasibility of treatment and reuse of the greywater, including kitchen waste in irrigation, toilet flushing, or street washing. Many types of research on greywater treatment did not include kitchen wastewater. Although most sewage systems in the Arab world collect wastewater from basins, bathtubs, showers and kitchens together in a combined drain pipe. Sometimes, BOD and TSS of greywater exceed that of municipal sewage. Table 1 shows the Water Quality Standards and Criteria for Domestic Water Recycling, according to WHO.

Table 1: the Water Quality Standards and Criteria for Domestic Water Recycling according to WHO

\begin{tabular}{|l|c|c|c|}
\hline Recycled for & Turbidity (NTU) & BOD5 (mg/L) & EC CFU/100 ml \\
\hline Toilet flushing & 5 & 10 & 0.3 \\
\hline Cleaning car & 10 & 15 & 0.3 \\
\hline Lawn irrigation & 10 & 20 & 0.3 \\
\hline
\end{tabular}

Fig. 1a and fig. 1b shows a photograph and schematic diagram for the pilot plant, it consists of :

1. Feeding tank: a $125 \mathrm{~L}$ PVC tank was placed on a table at height $2 \mathrm{~m}$. Asieve (5mm mesh sizes) was installed at the outlet of the tank, and it was used to screen the greywater. A manual valve installed in the outlet pipe of the tank was used to control the flow.

2. Greywater sources: high strength mixed greywater from the kitchen, washer, shower, and sink were the influents of the pilot plant

3. Pre-treatment stage: the steps in this stage included the following:

(a) Sedimentation: a PVC sedimentation tank $(25 \times 25 \times 40 \mathrm{~cm})$ was placed on a table at height $1.5 \mathrm{~m}$, where the solid materials settled. A manual valve installed in the bottom of the tank was used to send the settled solids to the drain.

(b) Fat and grease separation phase: a $20 \mathrm{~L}$ polyethene barrel were used to separate fat and grease from the rest of the influent. The fat and the grease floated on the water surface and were scraped, whereas the lower part of the water was siphoned off and moved by gravity to the main granular media filters. Submersible air blower was used to supply air to the barrel surface.

(c) A sample port was provided after the pre-treatment stage.

4. Main treatment stage: the media filters MF's is the main treatment stage. The dimensions of the MF were $0.1 \mathrm{~m}$ diameter $* 0.3 \mathrm{~m}$ height.

5. Media of the filters:

(a) Sand: local sand was used of effective size varies from $0.35 \mathrm{~mm}$ to $1.2 \mathrm{~mm}$.

(b) Sand and Zeolite: due to the fast clogging of the sand media alone, $50 \%$ by volume, of zeolite was 
mixed with sand to prevent fast clogging.

(c) Medium-size volcanic tuff (Zeolite) 7-14 mm in diameter was used as the filter media. Black and Red Zeolite were used separately in the first run, and they were mixed together in the next runs.

(d) Date stones activated carbon (DSAC): activated carbon was prepared in the lab, then crushed to size 3 $\mathrm{mm}-5 \mathrm{~mm}$.

6. A sample port was provided at the end of the filtration stage.

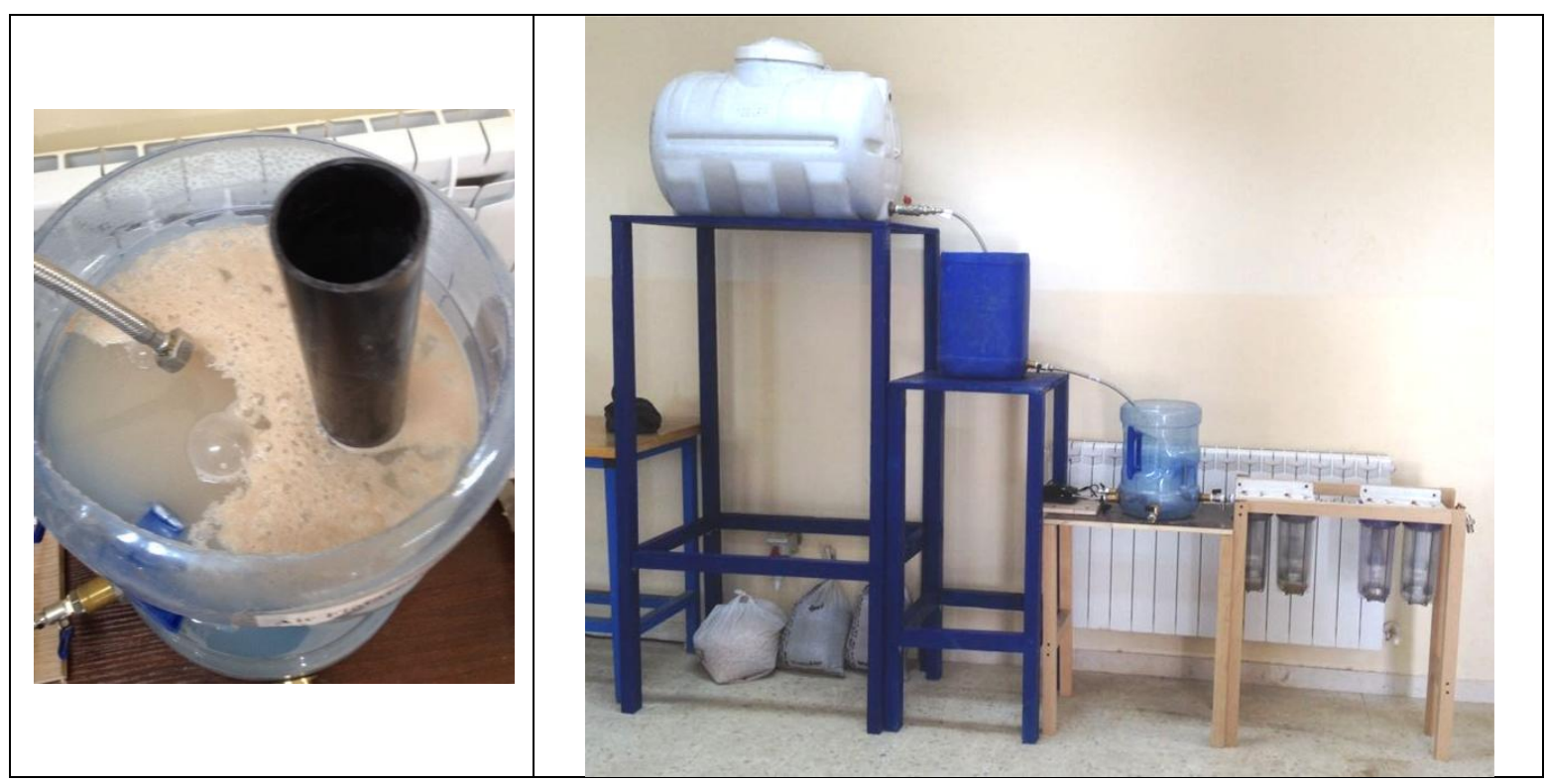

Fig.1a: photograph of the pilot plant and flotation tank

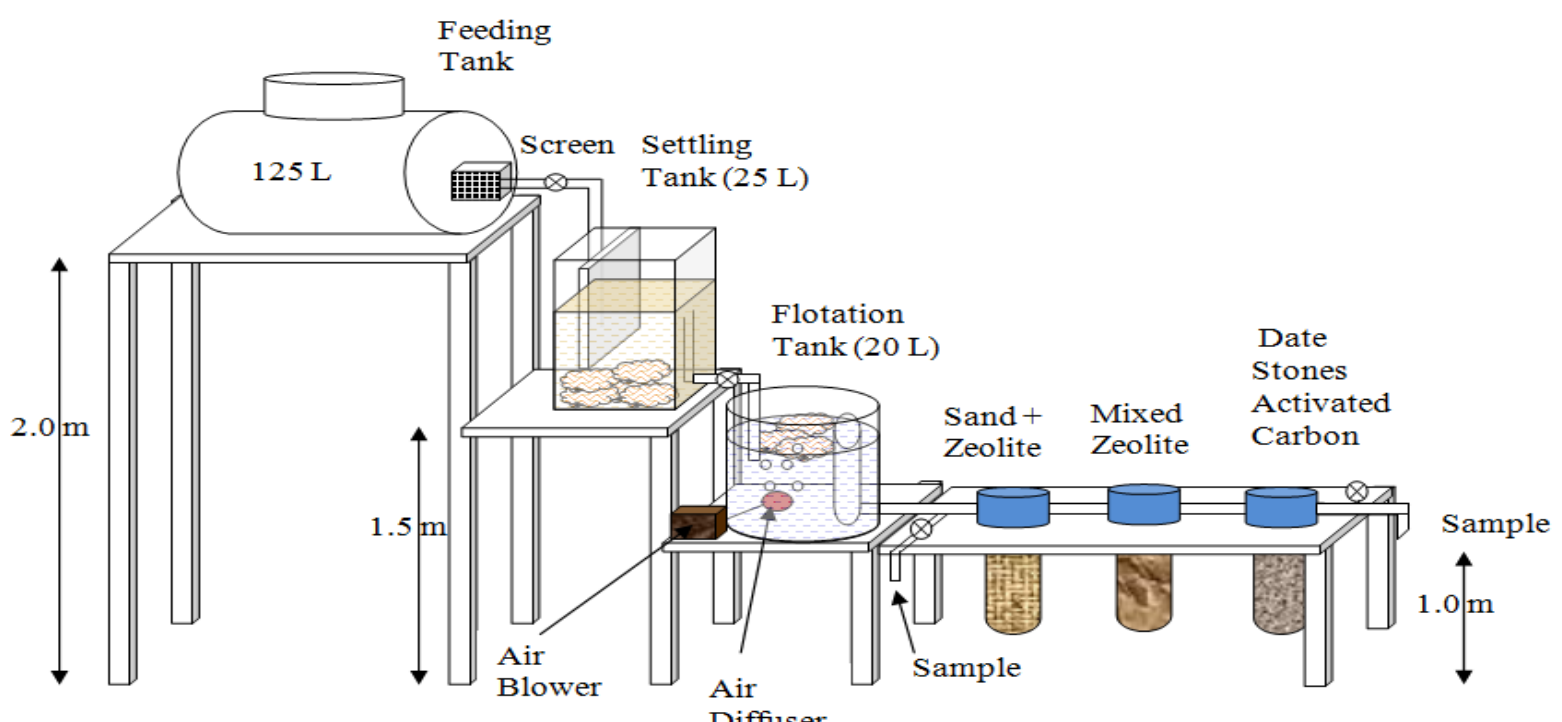

Fig.1b: schematic diagram of the pilot plant

Studied samples were collected from 3 residential buildings, each building contains 8 households. Samples were collected and mixed to be an average of the greywater. Different samples were collected for each stage.

A local supplier provided us with Red and black Zeolite. Both Red and Black zeolite were sieve-analyzed according to ASTM (1998) and were then washed and dried. Zeolite grain size distribution ranged from 7 to $14 \mathrm{~mm}$, other sizes were neglected. Table 2 and Table 3 show the physical and chemical properties of Black and Red Zeolite. Fig. 2 show a photograph of the Red zeolite.

Table 2: Chemical and physical properties of black Zeolite

\begin{tabular}{|c|c|c|c|c|c|c|c|}
\hline Parameter & $\mathrm{SiO} 2$ & $\mathrm{~A} 12 \mathrm{O} 3$ & $\mathrm{CaO}$ & $\mathrm{K} 2 \mathrm{O}$ & $\mathrm{P} 2 \mathrm{O} 5$ & $\mathrm{Na} 2 \mathrm{O}$ & $\mathrm{FeO}$ (total) \\
\hline Percentage $\%$ & $43.30 \%$ & $14.10 \%$ & $7 \%$ & 2 & $1.50 \%$ & $0.10 \%$ & $9.90 \%$ \\
\hline Parameter & $\begin{array}{c}\text { Water } \\
\text { absorption }\end{array}$ & Unit weight & $\begin{array}{c}\text { Specific } \\
\text { gravity }\end{array}$ & Void ratio & Porosity $\%$ & & \\
\hline Unit & $8.5-10.8 \%$ & $1010 \mathrm{~kg} / \mathrm{m} 3$ & $\begin{array}{c}1.56-1.80 \\
\mathrm{gm} / \mathrm{cm} 3\end{array}$ & 17.54 & $14.93 \%$ & & \\
\hline
\end{tabular}


Table 3: Chemical and physical percentage of Red Zeolite

\begin{tabular}{|c|c|c|c|c|c|c|c|}
\hline Parameter & $\mathrm{SiO} 2$ & $\mathrm{Al} 2 \mathrm{O} 3$ & $\mathrm{CaO}$ & $\mathrm{K} 2 \mathrm{O}$ & $\mathrm{MgO}$ & $\mathrm{Na} 2 \mathrm{O}$ & $\mathrm{Fe} 2 \mathrm{O} 3$ \\
\hline Percentage $\%$ & $42.70 \%$ & $13.90 \%$ & $9.80 \%$ & $1.90 \%$ & $9.20 \%$ & $2.10 \%$ & $13.90 \%$ \\
\hline Parameter & $\begin{array}{c}\text { Water } \\
\text { absorption }\end{array}$ & Unit weight & $\begin{array}{c}\text { Specific } \\
\text { gravity }\end{array}$ & Void ratio & Porosity \% & & \\
\hline Unit & $9.2 \%$ & $980 \mathrm{~kg} / \mathrm{m} 3$ & $1.79 \mathrm{gm} / \mathrm{cm} 3$ & ----- & ----- & & \\
\hline
\end{tabular}

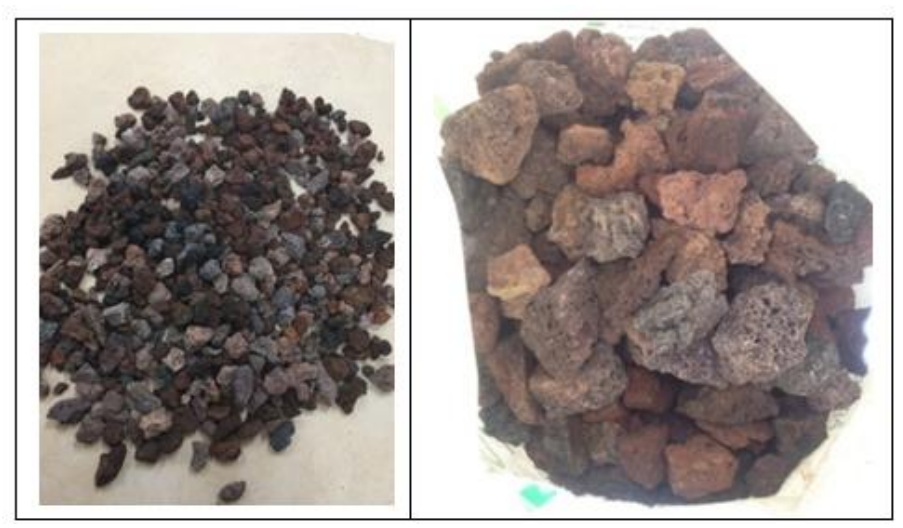

Fig2: a photograph of the mixed Zeolite and Red Zeolite.

Date stones are oblong hard stones of variable lengths weighing about one gram. They are made of corneous albumen and protected by cellulosic envelope [37].

Date stones from local Date Factory have been utilized as a source of the studied date stones. Activated carbons were prepared according to the following procedure. Once date stones are separated, washed with distilled water, they were dried to $105 \mathrm{C}^{\circ}$ overnight. Then it heated to $150 \mathrm{C}^{\circ}$ to be activated carbon.A grinding operation was then carried out leading to the obtention of granular particles having a diameter less than 4mm. DSAC was shown in Fig.3.

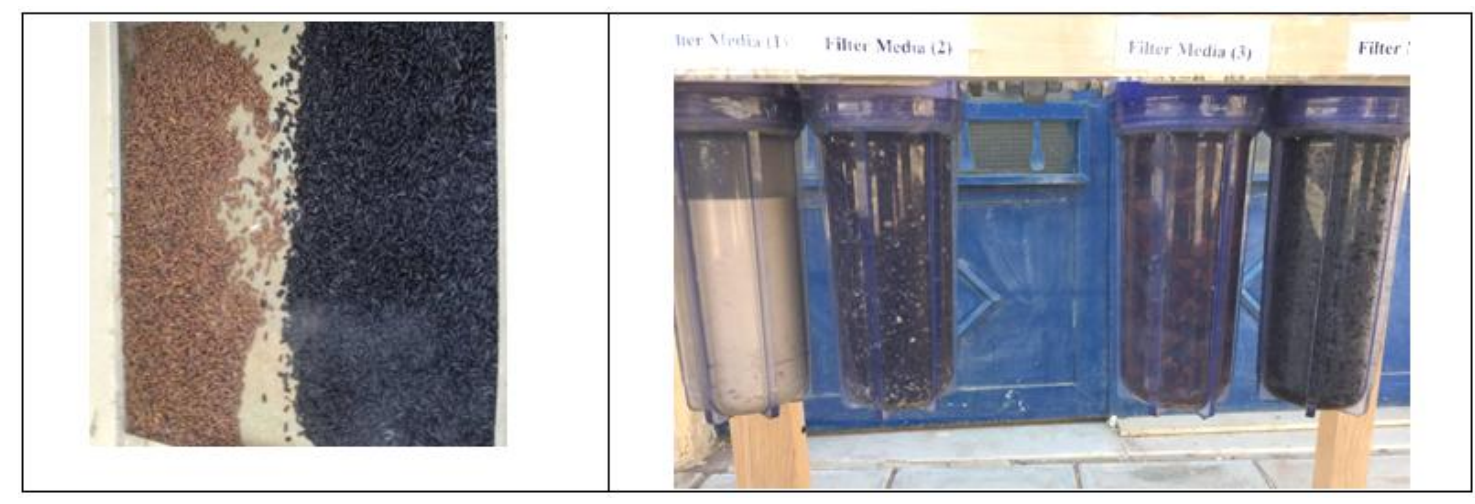

Fig3a: A Photograph of the date stones and DSAC

Fig3b: Filter medias

The experimental program was conducted through three stages, pre-treatment stage, main filtration stage and performance stage. The pre-treatment stage included screening, settling and flotation processes. The main filtration stage was conducted in two runs; the first run was achieved to determine the efficiency of each single filtration media. The second run was conducted to determine the best series of combined filtration, aiming to know the best arrangement of the unique filters in a series. The third stage was achieved to understand the combined efficiency of the best series of filters over time. The influent flow rate used was $0.33 \mathrm{~L} / \mathrm{min}$. Many parameters were measured during this study, TSS, BOD, COD, Turbidity, PH and DO. The samples were analyzed according to Standard Methods for the Examination of Water and Wastewater.

\section{RESULTS AND DISCUSSION}

To study the greywater treatment in our Arab countries and in some other countries which used the kitchen sink grinder ...etc, the kitchen waste must be considered in the greywater. In this study, including kitchen water in the greywater stream played a major role in increasing the concentration of organic contaminants and TSS. This was in agreement with the findings of prior studies that found that excluding kitchen water significantly reduced the organic load and total solids [38;39; 40].

\subsection{Stage 1,Pre-treatment:}

This phase measured the combined efficiency of sedimentation and flotation processes, the sedimentation process was held to separate most of suspended solids and part of the BOD and COD, while, the solids that cannot be precipitated like grease, oil, fats 
or colloidal matter, were exposed to air in the flotation tank, these two steps were absolutely necessary to prevent clogging in the main filtration stage. Fig.4 shows the raw greywater influent parameters TSS, BOD and COD in mg/L and the effluent of the same parameters, in addition to the combined removal efficiency of the sedimentation and flotation processes. Results show that BOD/COD was about 0.5; the removal efficiency of BOD was more than that of COD. Sedimentation and flotation remove about $45 \%$ of TSS and decrease the organic load of BOD by about $37 \%$ and of COD by about $35 \%$.

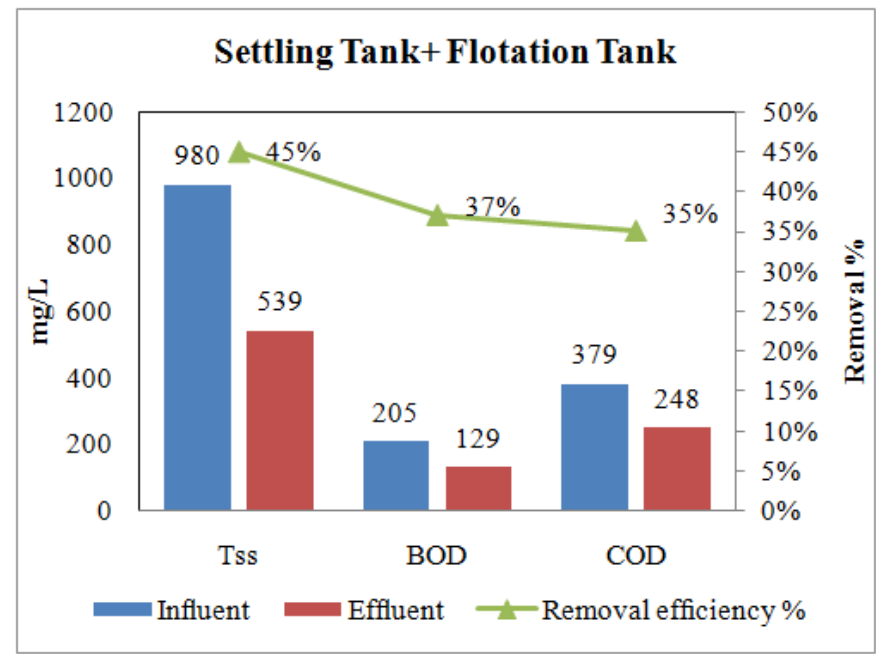

Fig. 4: The pre-treatment, influent, effluent and removal efficiency of TSS, BOD and COD.

\subsection{Stage 2,main filtration:}

In this main stage of filtration, a comparison study was achieved to determine the efficiency of each filtration media, aiming to use these filters in a series to achieve optimum overall removing efficiency And to know the mechanism of removal of different parameters for each media of filtration. This study was achieved on two runs

\subsubsection{Run1, determining the best single filtration media:}

Five different filtration media were tested, sand, sand mixed with zeolite (SMZ), Date stones activated carbon (DSAC), Black zeolite and Red zeolite. During the experiment, Sand filter gave the best performance in removal action, but due to the high concentration of TSS about $500 \mathrm{ppm}$, the sand filter suffered blockage problem. In order to avoid the problem of clogging in the sand filter, one-third of the sand volume was replaced with mixed red and black zeolite.

The results of the concentrations and removal efficiencies of TSS, BOD and COD are shown in Fig.5a, 5b and 5c. Results show that SMZ significantly reduced TSS, BOD COD, and in their effluents. The removal efficiency of these parameters reached $89 \%, 83 \%$, and $79 \%$, respectively, as compared to the DSAC where they reached $81 \%, 71 \%$, and $68 \%$, respectively. This may due to the double effect of the excellent cavity in the sand, in addition to the ability of zeolite to catch the particles in their cages. These results agree with [41].

The findings indicated that the removal mechanism of the pollutants by DSAC is dependent on the adsorption process proceeding via the surface functional groups available on DSAC,[42].

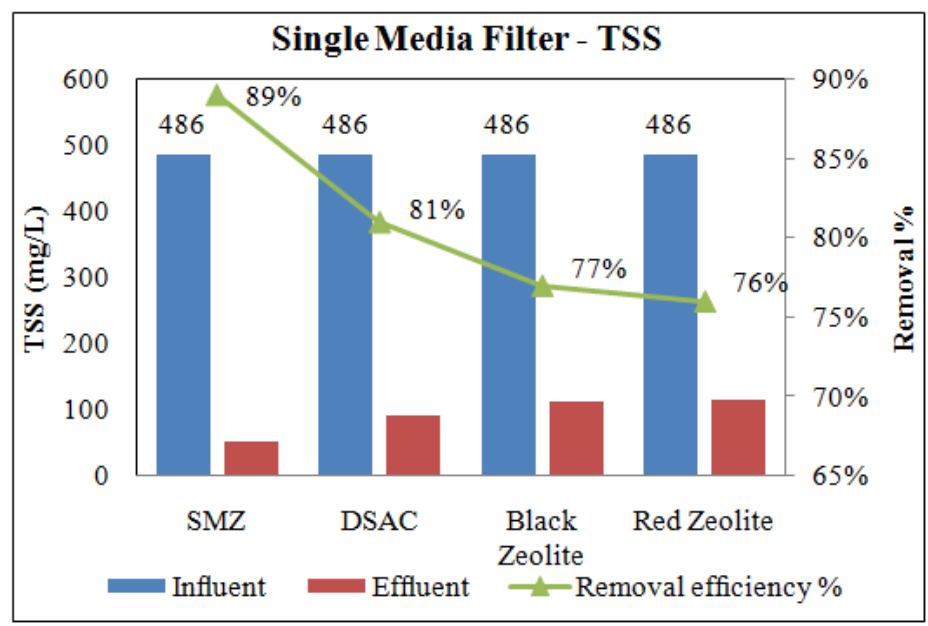


Fig. 5a: influent, effluent and removal efficiency of TSS, for Run1.

No difference in treatment efficiencies was found when analyzing the results for Red and Black Zeolite, the difference between their physical and chemical properties make no effect on their ability on greywater treatment. Zeolite (Red and Black) was the third most effective medium, which resulted in an average 76.5\% reduction in TSS, 65.5\% reduction in BOD and 62.5\% reduction in COD. During the next stages, Red Zeolite and black Zeolite were mixed together as one material.

Ion exchange is the main mechanism of removal by natural zeolite besides adsorption mechanism, and it can be explained that at a suitable condition's ion-exchange with the cations in the zeolite can be occurred [43].

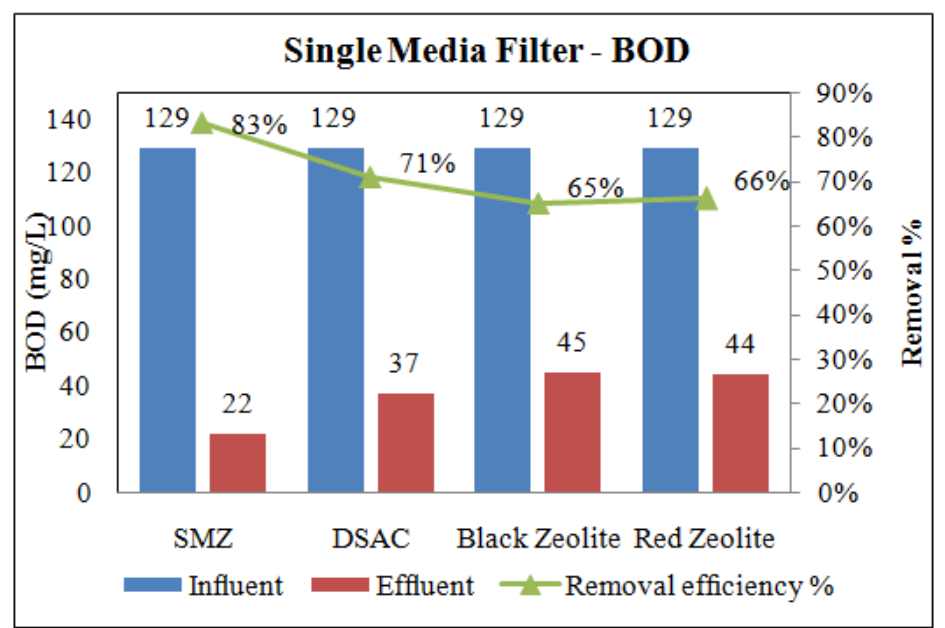

Fig. 5b: influent, effluent and removal efficiency of BOD, for Run1.

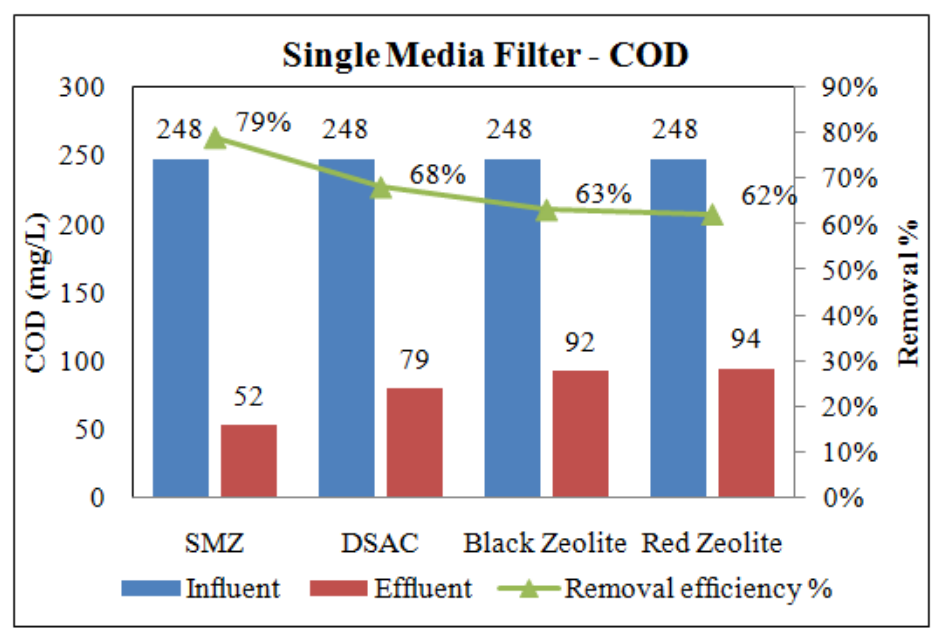

Fig. 5c: influent, effluent and removal efficiency of COD, for Run1.

\subsubsection{Run2, determining the best arrangement of single filters in a series:}

In this run, a comparison study was achieved to determine the best method of filters in a series to achieve optimum overall removing efficiency, and to know the best mechanism of removal of different parameters for each series. For this purpose, three series of filters were used, Series1 (sand mixed with zeolite $(3: 1)+$ zeolite), Series2 (sand mixed with zeolite (3:1) +DSAC) and Series3 (sand mixed with zeolite $(3: 1)+$ Zeolite +DSAC).

The results of the experiments were shown in the following charts. Fig. 6a shows that the optimum removal efficiency of TSS is $98 \%$ for Series 3 and it was $93 \%$ for series 2 while the removal efficiency of the Series 1 was $91 \%$. It was showing that the best removal efficiency was in the case of Series3 that was containing mixed sand and zeolite as a fine media followed by a Zeolite which, catches and adsorbs the escaped particles and finally the date stones activated carbon, which adsorbs color and escaped particles from greywater and from zeolite itself. 


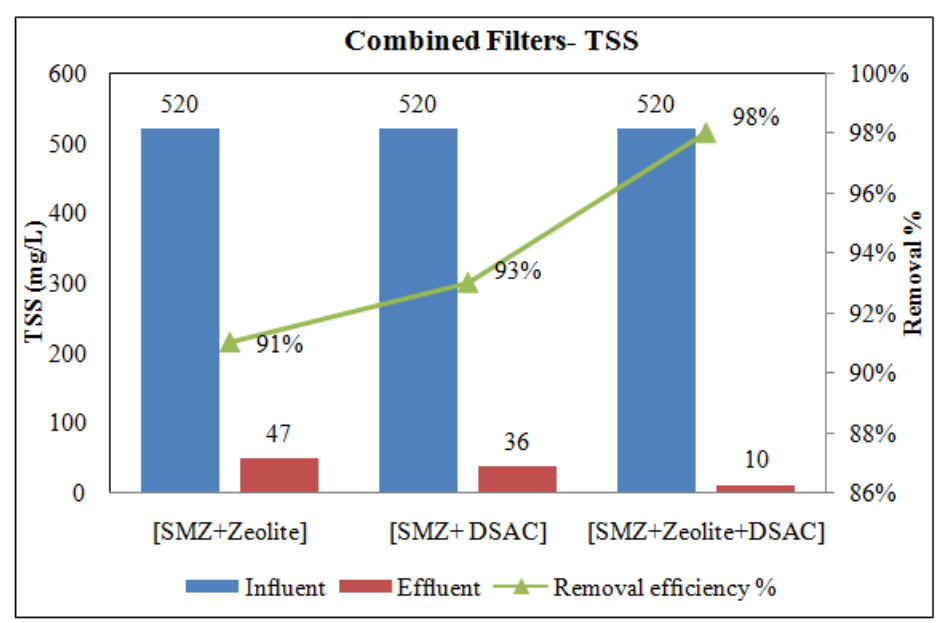

Fig. 6a: influent, effluent and removal efficiency of TSS, for Run2.

Fig. $6 \mathrm{~b}$ and $6 \mathrm{c}$ show that the optimum removal efficiency of BOD and COD were $95 \%$ and $93 \%$ at Series 3 and they were 88 $\%$ and $86 \%$ at series 2 while the removal efficiencies of the Series 1 were $85 \%$ and $82 \%$ respectively. It was showing that the best removal efficiency was in the case of Series3.

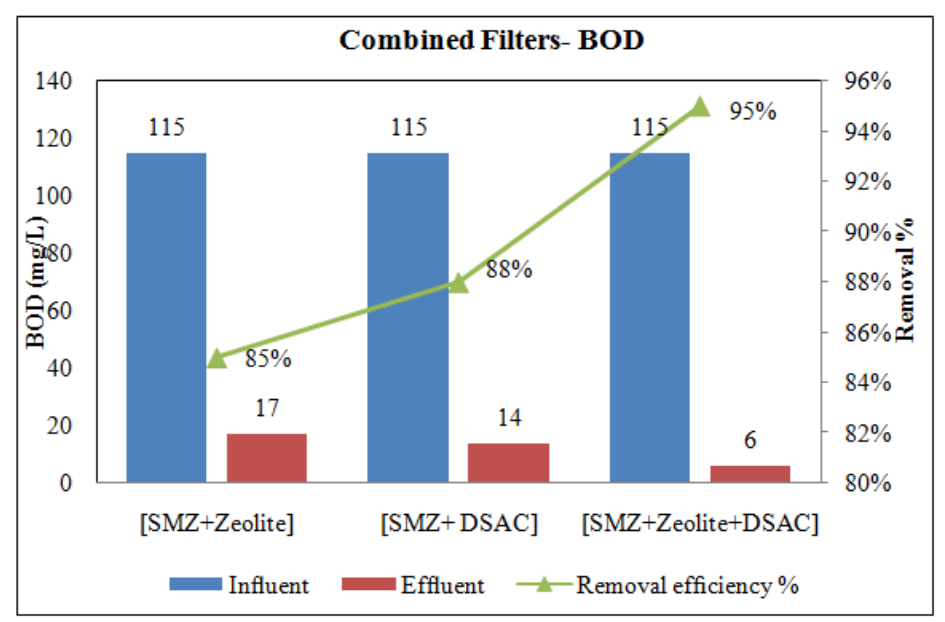

Fig. 6b: influent, effluent and removal efficiency of BOD, for Run2.

After this phase, the water will be re-used, so measuring of turbidity was essential to encourage people to reuse it. The results showed that the turbidity level was accepted at series 3 and series 2 according to the WHO standard, but at series 1 it was little above the standard limit which was 10 NTU for lawn irrigation. These results were shown in Fig.6d.

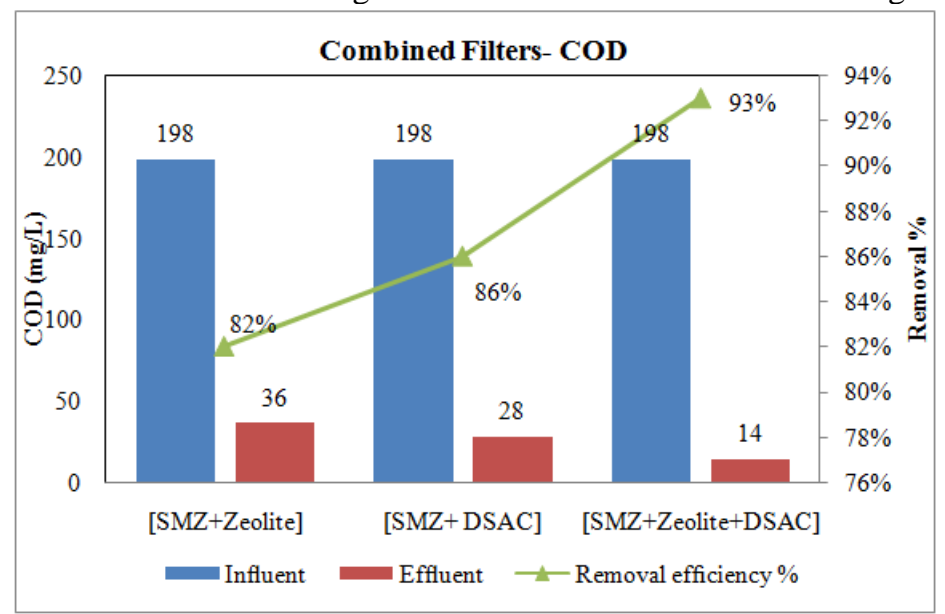

Fig. 6c: influent, effluent and removal efficiency of COD, for Run2. 


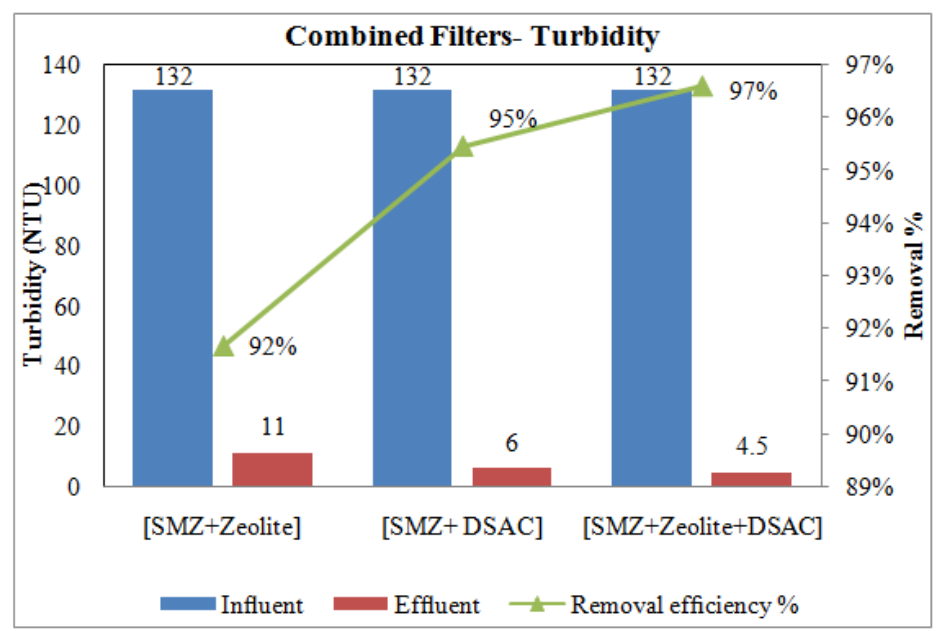

Fig. 6d: influent, effluent and removal efficiency of turbidity, for Run2.

\subsection{Stage 3, Understanding the performance of the series of filters over time:}

During this stage combined efficiency of best series of filters Series 3 overtime was tested. The influent flow rate used was the same $0.33 \mathrm{~L} / \mathrm{min}$. TSS, BOD and COD were monitored hourly along 6 hours. Fig. 7a, 7b and 7c show these results. Results show a decrease in removal efficiency of TSS with the time by about $6 \%$ during 6 hours. A change in the slope of the removal efficiency curve was noticed after 3 hours, this could be explained by a little clogging, resulting in a little decrease in flow. This result leads to the necessity of backwash after the losses of the head pressure.

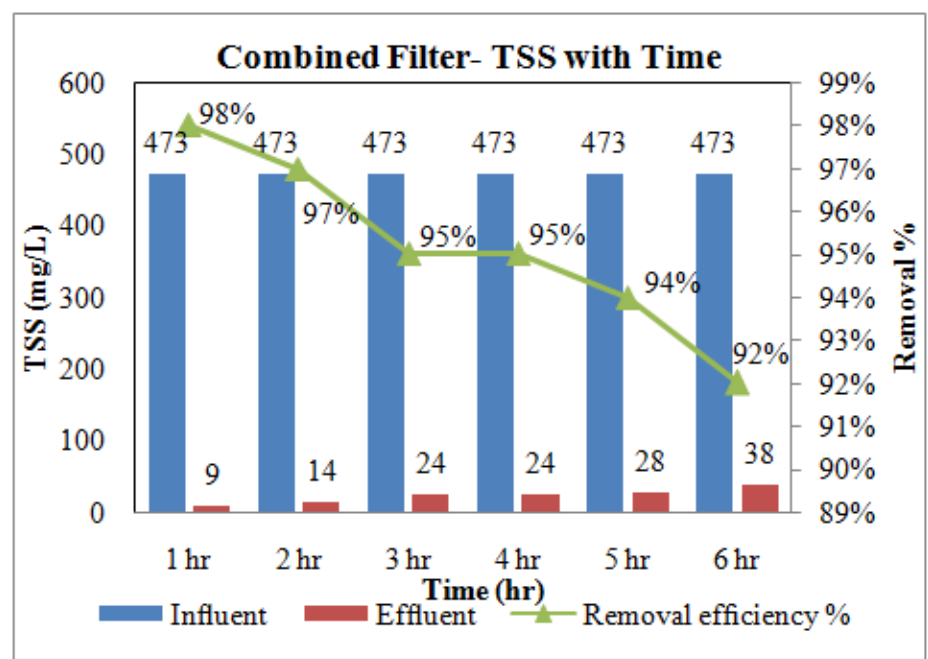

Fig. 7a: influent, effluent and removal efficiency of TSS over time, for Stage 3.

BOD and COD showed the same behavior as TSS, BOD lost $5 \%$ of its removal efficiency to be $90 \%$, and COD lost $6 \%$ of its removal efficiency to be $78 \%$.

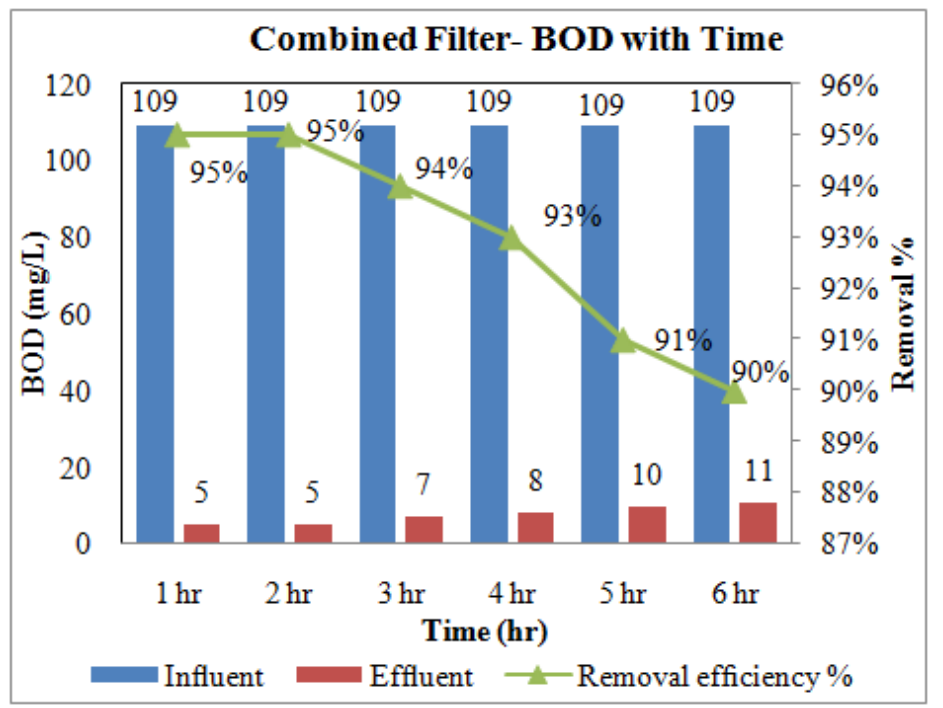


Fig. 7b: influent, effluent and removal efficiency of BOD over time, for Stage 3.

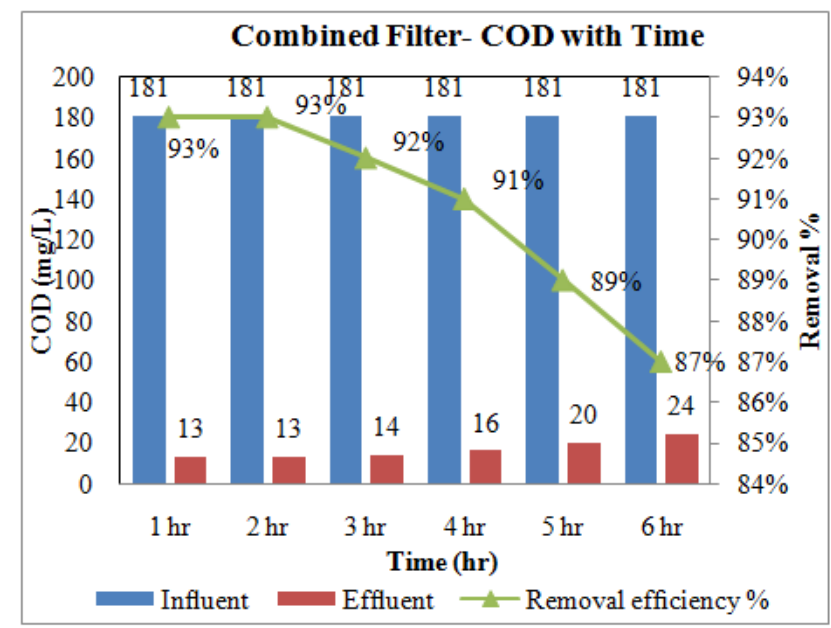

Fig. 7c: influent, effluent and removal efficiency of COD over time, for Stage 3.

Fig. $7 d$ shows the linear correlation between time on $\mathrm{X}$-axis and removal efficiency on $\mathrm{Y}$-axis with R-square value 0.95 , showing a very little error in the linear equation. From the equation the full blockage time for the Series could be predicted to be $89 \mathrm{hrs}$, after which the backwashes of the filters should be provided. This blockage time is theoretical because it was calculated as overall time for the series. Each medium has a different clogging time according to the effluent TSS concentration of the previous unit.

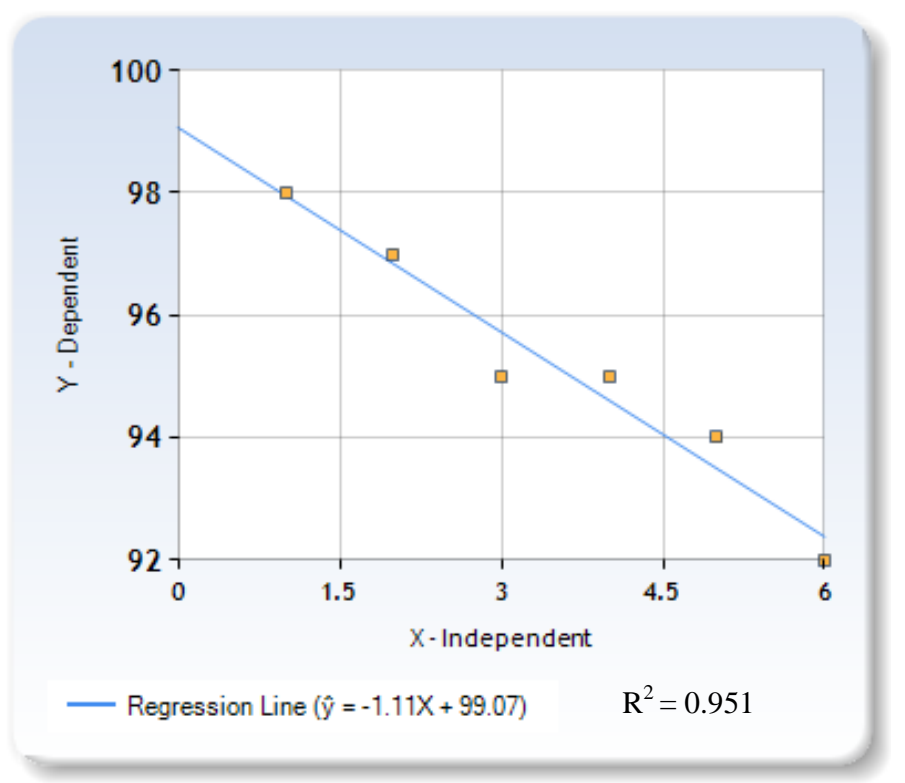

Fig. 7d: correlation between removal efficiency of TSS and time.

\section{CONCLUSIONS}

The simple design of the greywater treatment plant presented in this study was able to suggest a simple household treatment unit that could re-produce water for non-drinking purposes. When dealing with greywater treatment that includes kitchen waste, it was necessary to use pre-treatment prior to filtration to reduce organic load and prevent filters clogging. Sedimentation and flotation processes succeeded in reducing organic BOD loads by about 37\% and TSS by $45 \%$. Based on the results presented in this study, it could be concluded that the series of [sand mixed with Zeolite+ Zeolite +date stones activated carbon] was efficient in removing the studied organic pollutants and TSS from the raw greywater. The sand and DSAC combined filters were more efficient in treating organic contaminants and TSS than sand and Zeolite combined filters.

Regarding single filtration media, Sand mixed with Zeolite (SMZ) had the best removal efficiency more than DSAC or Zeolite. Zeolite exists in nature as natural rock, while DSAC is activated carbon made from a byproduct waste of date factory, and it has no cost except the energy required for turning it into activated carbon. Both of Zeolite and DSAC were right filter media, but DSAC removal efficiency was better than that of Zeolite.

The results showed that over time, the filtration efficiency decreases according to a linear equation. This linear equation could be deduced for any series of filters by testing it in a laboratory. $98 \mathrm{hr}$ is the theoretical time calculated for the blockage of the overall series but practically, blockage time for each filter media should be calculated separately within this series so, further studies are needed. 
Citation: Ahmed M. Abou Elmagd, The Synergistic Effect of Zeolite, Date Stones Activated Carbon and Sand in Treatment of Greywater Including Kitchen Waste. Journal of Applied Sciences Research, 15(4): 16-26.DOI: 10.22587/jasr.2019.15.4.3

\section{CONFLICT OF INTEREST}

Authors declare no conflict of interest

\section{REFERENCES}

[1] Etchepare, R. \& van der Hoek, J. P., (2015)," Health risk assessment of organic micropollutants in greywater for potable reuse". Water Research 72, 186-198.

[2] Laaffat, J., Aziz, F., Ouazzani, N., \& Mandi, L. (2019).’Biotechnological approach of greywater treatment and reuse for landscape irrigation in small communities". Saudi Journal of Biological Sciences. doi:10.1016/j.sjbs.2017.01.006.

[3] Nolde, E., (2000), "Greywater reuse systems for toilet flushing in multistory buildings-over ten years experience in Berlin". Urban Water 1, 275-284.

[4] Gross, A., Shmueli, O., Ronen, Z. \& Raveh, E., (2007)," Recycled vertical flow constructed wetland (RVFCW)—a novel method of recycling greywater for irrigation in small communities and households". Chemosphere 66, 916-923.

[5] Ammari, T. G., Al-Zu’bi, Y., Al-Balawneh, A., Tahhan, R., Al-Dabbas, M., Ta’any, R. A. \& Abu-Harb, R., (2014), “An evaluation of the re circulated vertical flow bioreactor to recycle rural greywater for irrigation under arid Mediterranean bioclimate". Ecological Engineering 70, 16-24.

[6] Li, F., Wichmann, K. \& Otterpohl, R., (2009), "Review of the technological approaches for grey water treatment and reuses". Science of the Total Environment, 407, 3439-3449.

[7] Boyjoo, Y., Pareek, V. K. \& Ang, M., (2013), “A review of greywater characteristics and treatment processes”. Water Science \& Technology 67, 1403-1424.

[8] Kraljevic Paveli ' c S, Simovi ' c' Medica J, Gumbarevic D, Filoševi ' c A, ' Pržulj N and Pavelic K (2018) "Critical Review on Zeolite Clinoptilolite Safety and Medical Applications in vivo". Front. Pharmacol. 9:1350. doi: 10.3389/fphar.2018.01350.

[9] Md Nuruzzaman, Yanju Liu , Mohammad Mahmudur Rahman ,Rajarathnam Dharmarajan ,Luchun Duan ,Abul Faiz Md Jamal Uddin ,Ravi Naidu.,(2019), “Chapter 4 - Nanobiopesticides: Composition and preparation methods"., Perspectives, Pages 69-131

[10] Endo M, Yoshikawa E, Muramatsu N, Takizawa N, Kawai T, Unuma T.(2013), ”The removal of cesium ion with natural Itaya zeolite and the ion exchange characteristics". J. Chem. Technol. Biotechnol.; 88(9): 1597-1602.

[11] Lei L C, Li X J, Zhang X W.(2008)," Ammonium removal from aqueous solutions using microwave-treated natural Chinese zeolite". Sep. Purif. Technol.; 58(3): 359-366.

[12] Ran X, Duan N, Zhang Y H, Li B M, Liu Z D, Lu H F.. (2015), “ Nitrogen and phosphorous adsorption from posthydrothermal liquefaction wastewater using three types of zeolites". Int J Agric \& Biol Eng; 8(5): 86-95.

[13] Schouten, N. (2009),'Reuse of laundry rinsing water by low cost adsorption technology". Unpublished PhD thesis, Eindhoven University of Technology, Eindhoven.

[14] Salager, J., (2000), Surfactants: Types and uses no.2. Universidad delas Andes, Venezuela.

[15] James, D. T. K., Ifelebuegu, A. O., (2018)," Low Cost Sustainable Materials for Grey Water Reclamation", Water Science \& Technology (3): 667-678.

[16] Widiastuti, N., Wu, H., Ang, M. \& Zhang, D., (2008)," The potential application of natural zeolite for greywater treatment”. Desalination 218, 271-280.

[17] Apreutesei, R.E., Catrinescu, C. \& Teodosiu, C., (2008), 'Surfactantmodified natural zeolites for environmental applications in water purification". Environmental Engineering and Management journal 7 (2), 149-161.

[18] Uta Linke, G., (2014), Experiment Instruction. Gant Hamberg, Germany.

[19] F. Mechati, C. Bouchelta, M.S. Medjram, R. Benrabaa, N. Ammouchi, (2015), "Effect of hard and soft structure of different biomasses on the porosity development of activated carbon prepared under N2/microwave radiations", J. Environ. Chem. Eng., 3, 1928-1938.

[20] Rashed, M.N., (2013), Organic Pollutants - Monitoring, Risk and Treatment. Intech.

[21] S.Á. Torrellas, R.G. Lovera, N. Escalona, C. Sepúlveda, J.L. Sotelo, J. García, (2015), “Chemical-activated carbons from peach stones for the adsorption of emerging contaminants in aqueous solutions", Chem. Eng. J., 279, $788-798$.

[22] D.A.S. Maia, K. Sapag, J.P. Toso, R.H. López, D.C.S. Azevedo, C.L.C. Jr., G.Zgrablich, (2010), "Characterization of activated carbons from peach stones through the mixed geometry model, Microporous", Mesoporous Mater., 134 ,181-188.

[23] T. Depci, Y. Onal, K.A. Prisbrey, (2014), "Apricot stone activated carbons adsorption of cyanide as revealed from computational chemistry analysis and experimental study", J.Taiwan Inst. Chem. Eng., 45, 2511-2517.

[24] B. Petrova, T. Budinova, B. Tsyntsarski, V. Kochkodan, Z. Shkavro, N. Petrov, (2010), "Removal of aromatic hydrocarbons from water by activated carbon from apricot stone", Chem. Eng. J., 165, 258-264.

[25] R. Hazzaa, M. Hussein, (2015), “Adsorption of cationic dye from aqueous solution onto activated carbon prepared from olive stones", Environ. Technol. Innovation, 4, 36-51

[26] M. Berrios, M.Á. Martín, A. Martín, (2012), “Treatment of pollutants in wastewater: Adsorption of methylene blue onto olive-based activated carbon", J. Ind. Eng. Chem., 18, 780-784.

[27] P. Nowicki, J. Kazmierczak, R. Pietrzak, (2015), Comparison of physicochemical and sorption properties of activated carbons prepared by physical and chemical activation of cherry stones, Powder Technol., 269, 312-319. 
[28] M. Olivares-Marín, C. Fernández-González, A. Macías-García, V. Gómez-Serrano, (2012), "Preparation of activated carbon from cherry stones by physical activation in air. Influence of the chemical carbonisation with H2SO4", J. Anal. Appl. Pyrolysis, 94, 131-137.

[29] I. Okman, S. Karagöz, T. Tay, M. Erdem, (2014), "Activated carbons from grape stones by chemical activation with potassium carbonate and potassium hydroxide", Appl. Surf. Sci. 138-142.

[30] M. Al Bahri, L. Calvo, M.A. Gilarranz, J.J. Rodriguez, (2012), “Activated carbon from grape stones upon chemical activation with phosphoric acid: Application to the adsorption of diuron from water”, Chem. Eng. J., 203 , 348-356.

[31] M.L. Sekirifa, M. Hadj-Mahammed, S. Pallier, L. Baameur, D. Richard, A.H. Al-Dujaili, (2013), "Preparation and characterization of an activated carbon from a date stones variety by physical activation with carbon dioxide", J. Anal. Appl. Pyrolysis, 99, 155-160.

[32] E.A. El-Sharkawy, A.Y. Solimanb, K.M. Al-Amer, (2007), "Comparative study for the removal of methylene blue via adsorption and photocatalytic degradation", J. Colloid Interface Sci., 310, 498-508.

[33] M.J. Ahmed, S.K. Theydan, (2014), "Adsorptive removal of p-nitrophenol on microporous activated carbon by FeCl3 activation: equilibrium and kinetics studies", Desalination Water Treat., 1-10.

[34] H.B. Amor, M. Ismail, (2015), "Adsorption of chromium (VI) on activated carbon prepared by acid activation of date stones", Int. J. Sci. Res. (IJSR), 4 , 309-314.

[35] R. Briones, L. Serrano, R.B. Younes, I. Mondragon, J. Labidi, (2011), "Polyol production by chemical modification of date stones". Ind. Crops. Prod. $34,1035-1040$.

[36] M.H. El-Naas, S. Al-Zuhair, M.A. Alhaija, (2010), "Removal of phenol from petroleum efinery wastewater through adsorption on date-pit activated carbon", Chem. Eng. J., 162, 997-1005.

[37] Gherairi Yamina, Amrane Abdeltif, Touil Youcef, Hadj Mahammed.,(2013)," A Comparative Study Of The Addition effect Of Activated Carbon Obtained From Date Stones On The Biological Filtration Efficiency Using Sand Dune Bed." Energy Procedia 36, $1175-1183$.

[38] Eriksson, E. \& Donner, E., (2009), Metals in greywater: sources,presence and removal efficiencies. Desalination 248, 271278.

[39] Al-Hamaiedeh, H. \& Bino, M. (2010), Effect of treated grey waterreuse in irrigation on soil and plants. Desalination 256, $115-119$.

[40] Assayed, A., Chenoweth, J. \& Pedley, S.,(2014), Drawer compactedsand filter: a new and innovative method for on-site greywater treatment. Environmental Technology 35, 2435-2446.

[41] Pushpa J. Samkutty \& Ronald H. Gough (2002) "Filtration Treatment Of Dairy Processing Wastewater", Journal of Environmental Science and Health, Part A, 37:2, 195-199, DOI: 10.1081/ESE-120002582.

[42] Mohd Adib Mohammad Razi, Adel Al-Gheethi, Mohammed Al-Qaini \& Anwar Yousef., (2018), "Efficiency of activated carbon from palm kernel shell for treatment of greywater", Arab Journal of Basic and Applied Sciences, 25:3, 103-110, DOI: 10.1080/25765299.2018.1514142.

[43] Nurul Widiastuti , Hongwei Wu, Ha Ming Ang, Dongke Zhang .,(2011), Desalination 277, 15-23. 